\title{
Mosan: Combining Circularity and Participatory Design to Address Sanitation in Low-Income Communities
}

\author{
Mona Mijthab $^{1,2} \cdot$ Raluca Anisie $^{1}$ (D) $\cdot$ Omar Crespo $^{1}$
}

Received: 19 March 2021 / Accepted: 20 September 2021 / Published online: 8 November 2021

(C) The Author(s) 2021

\begin{abstract}
The health and environmental impact of unsafe sanitation affects more than half of the world's population. The lack of access to safe sanitation affects disproportionately rural populations in low- and middle-income countries, where progress is also shown to be slower. The sheer scale of the problem, combined with the variability of climate, geographies, and socioeconomic conditions, requires a variety of adaptable, scalable, centralized, and decentralized solutions working cohesively. This paper presents the case of Mosan, an off-grid, market-based sanitation solution, in order to display how such sanitation approaches can contribute to bridge this gap by addressing the communities most at risk. Mosan is a decentralized, circular sanitation solution encompassing the whole sanitation chain from containment, collection, transport, transformation, and reuse. Focused on community-scale systems, Mosan is applying participatory design principles and co-creation to enable community engagement, raise awareness, trigger creativity, and support local innovation.
\end{abstract}

Keywords Ecosan · Container-based sanitation · Circular economy $\cdot$ Biochar $\cdot$ Co-creation · Participatory design

Raluca Anisie

ra@mosan.ch

Mona Mijthab

mm@mosan.ch; mona.mijthab@zhdk.ch

Omar Crespo

oc@mosan.ch

1 Mosan, Guatemala City, Guatemala

2 Zurich University of the Arts (ZHdK), Zurich, Switzerland 


\section{Introduction}

Access to safe sanitation has been a challenge ever since organized urban conglomerates started to form. Sanitation solutions such as pit latrines have existed since the fourth millennium BC in the Middle East and the second millennium BC in Greece and have been adopted and further improved by Romans into water pipes, baths, and sewers [1,2]. With the rise in population during the industrial revolution, many cities in Europe and North America experienced various sanitation crises due to poor sanitary conditions linked to systems that were not anymore adapted to the needs of the new scale of urban areas [3]. Today, the highest population growth originates in low- and middle-income countries, where safe sanitation coverage is low and progress uneven [4]. Building and operating sewerage systems in these contexts pose complex challenges providing scope to the emergence of alternative, locally adapted mix of solutions and approaches $[5,6]$.

The transition from Millennium Development Goals (MDGs) to the Sustainable Development Goals (SDGs) granted the water and sanitation sector greater prominence. With this renewed focus, sanitation is positioned as both a public and environmental health matter, sustainable management of the sanitation chain becoming equally important as access to the service itself (SDG 6: Ensure availability and sustainable management of water and sanitation for all) $[5,6]$. Targets 6.2 (access to adequate and equitable sanitation and hygiene services) and 6.3 (halving the proportion of untreated wastewater and substantially increasing recycling and safe reuse globally) put the focus on the whole sanitation chain from containment to disposal.

\section{Market-Based Sanitation Services}

Encouraging market-based approaches is one way of facilitating the inclusion of the whole sanitation chain into sanitation solutions. Identifying opportunities of economic gain as the revalorization of waste products can be a financial incentive and offset some of the sanitationassociated costs. However, up to date, none of these end-products managed to provide enough revenues to recover the investment and operational costs needed to produce them [7]. Often, the market is too competitive to allow selling the products at their real costs. This is the case for the fertilizer market which is notorious for high subsidies [8]. Also, there is a lack of regulation and policy around waste reuse which adds to the hurdle of registering and commercializing these products [9]. Commercializing higher value-added products in niche, reuse friendly markets could perhaps be a potential viable option.

A market-based sanitation service works from the premise that proven demand leads to purchasing behavior and willingness to pay. However, in the case of sanitation, market failures stemming from the mismatch between expression of demand and perceived value of the service are not uncommon, i.e., the intended beneficiaries may recognize a need but may not be willing to pay for the product [10]. While many people do pay private providers for the construction of latrines or other on-site sanitation systems (OSS) [11], their choice is largely influenced by the cultural and social context and doesn't necessarily follow a pragmatic reasoning [10]. Normally, nor the costs of the whole service chain neither externalities as the environmental impact are factored in their decisions [11]. In low-income areas, most valued innovations tend to be those that offer instant gratification or directly increase the income-generating capacity [10]. Sanitation however has a longer-term effect on the wellbeing of the families, generating benefits that are not always perceived as being correlated with 
it, such as less disease, more security and dignity, and increased school attendance [12]. Therefore, sanitation entrepreneurs need to go a step further into creating their market, namely, a real demand among end-users for their innovation [10]. This entails a deep understanding of the local ecosystem and investment in education, local capacities, and trust building, among others [10].

It is widely recognized that sanitation services need government support, direction, and legislative integration [11]. Historically, market-creating innovations have catalyzed institutional change, which normally act as an adaptive response to the changing environment [13]. Therefore, it is likely that the more examples of private, market-based sanitation approaches demonstrate scalability and impact the more governments will create an enabling environment for them to operate. However, market-creating innovations are difficult to establish, costly, and require consistent work over long periods of time [13]. Spurring and sustaining these innovations and their diffusion would certainly require a combination of efforts of multiple sector stakeholders, cooperation, advocacy, and adequate financing [7, 9, 14].

\section{Container-Based Sanitation}

Container-based sanitation (CBS) is one example of a market-based approach to sanitation. In the past 10 years, different entrepreneurs started implementing CBS services in various countries such as in Kenya, Ghana, Haiti, Madagascar, Peru, and India. While CBS approaches vary in their implementation, business model, and technology, essentially, they are all trying to offer a viable alternative to conventional sanitation systems. CBS services are mostly designed as circular economy solutions, showing climate mitigation potential and, thus, contributing to reaching global carbon emission targets $[15,16]$. In CBS services, human excreta are usually collected in mobile containers and transported to treatment facilities when full. The excreta are then transformed into reusable products. The model ensures safe disposal and limits anaerobic digestion of human excreta throughout the supply chain given the short containment phase compared to other OSS [17]. CBS has the potential to operate as a smallscale installation, managed by community-based organizations, thus avoiding the massive infrastructure investment needed for conventional sewerage $[9,14]$. This could contribute to speeding up the roll out of sanitation services which are often blocked by reduced investment capacity, and low political will [14]. While initially implemented as stand-alone solutions, in the past years, a higher degree of integration with other city-wide inclusive sanitation (CWIS) systems has been observed. For example, some CBS companies integrated pit latrine sludge collection or organic waste collection $[9,14]$.

While CBS has been present for more than 10 years, the approach has been slow to scale. This is primarily attributable to the novelty of a full value-chain market-based sanitation approach, meaning that the (i) intended beneficiaries have little experience in paying for these services which translates into low willingness and ability to pay, (ii) there is a lack of policy and regulatory frameworks for CBS as a sanitation solution as well as for the reuse of treated excreta, and (iii) there is a lack of business models for covering the costs of the full value chain service $[9,14]$. The social, cultural, and technical complexities of implementing sanitation in low-income areas have also contributed to this slow growth [14]. In most cases, CBS enterprises need to start from scratch by developing an entirely new value network around their product. Most CBS companies cover the whole supply chain from client education and sales to toilet design and production, collection service, and transformation technology. Most of the time, they integrate internally all the process steps of the service, and sometimes, they 
also need to fill in the infrastructure gaps that might hinder their ability to serve marginalized communities. The integration of services that are not necessarily core competencies of the company is needed in order to guarantee the quality of the service [9]. This means developing a wide and varied range of skills within the team [18]. As the approach matures, unbundling of some services and specialization along the value chain will perhaps allow companies to focus rather than attempt to do it all.

While studies have shown that CBS could scale cost-effectively $[9,19,20]$, its financial sustainability will most likely rely in the short term on a mix of earned revenues and public financing [9]. However, even though one cost-effectiveness assessment study has shown that CBS is the option with the lowest annual costs per household for providing safely managed sanitation, the approach lacks recognition and popularity with local governments [19]. Traditionally, governments think of sanitation as an infrastructure investment with high capital cost and smaller maintenance and operation costs. The fact that CBS cost structure is completely different leads to the perception that it is more expensive than the alternatives. Plus, this also means that government budgets and contracts are not adapted to these types of cash flows and investments [19]. To incentivize the formation of public-private partnerships, blended finance, outcome-based financing, and other SDG targeted financial instruments should be leveraged $[9,14,19]$. Lessons can be learned from the solar mini-grid or water sector where work has been done on establishing public-private partnerships in the form of risk sharing mechanisms and performance-based grants [21, 22]. Furthermore, the inclusion of a more diversified, yet complementary, offer to municipalities (as in the collection of OSS sludge or other waste) could help both in increasing the earned revenues as well as attracting the public office interest.

The recognition in 2018 of CBS by the Joint Monitoring Programme, the World Health Organization (WHO), and UNICEF's platform that monitors global WASH progress, as a type of improved sanitation, has been an important step in creating an enabling environment for these types of services to grow $[9,14]$. This will enable governments to consider and possibly support this solution when selecting sanitation systems.

Mosan is a social enterprise currently providing CBS services in indigenous communities on the shores of Lake Atitlán, Guatemala. The concept was born from a project starting in 2010 in Bangladesh closely involving the local community of peri-urban slums of Mymensingh. The goal of the project was to design a mobile toilet that would work under harsh conditions. Some of the visited communities were located above open water bodies like lakes or rivers, in flood-prone areas or on river dams. Designing a sanitation solution in those contexts asked for mobility, adaptability, and independence from water. Both the toilet and the service chain were further developed during projects in slums in Kenya and in a refugee camp in South Sudan, incorporating different cultural contexts and user preferences. A 1-year pilot project took place between 2018 and 2019 in Guatemala, servicing over 50 people in the indigenous community of Santa Catarina Palopó. Afterwards, the pilot has transitioned into a permanent service. Currently, Mosan is in the process of scaling up and expanding to further communities around Lake Atitlán and in Guatemala.

\section{The Mosan Circular Sanitation Solution}

Mosan addresses inadequate sanitation by providing an ecological, circular sanitation system. The Mosan solution includes the Mosan mobile urine-diverting dry-toilet appropriate for densely populated settlements or for areas where conventional sewerage systems fail, either 
due to difficult terrain, hard ground, lack of water, or investment capacity. Mosan ensures safe collection, containment, transport, and transformation of human excreta. The excreta are then valorized into products that can be commercialized. The illustration of the circular Mosan system is depicted in Fig. 1.

Mosan's concept grew from the vision of giving people a safe, and affordable sanitation service that is easy to use and install. The Mosan solution is designed to integrate high-quality standards. The goal is to provide a dignified and attractive sanitation solution that is perceived as modern progress and not associated with old-fashioned dry alternatives as pit latrines. The Mosan solution is also designed to enhance climate and social resilience for vulnerable communities - for situations such as floods when other sanitation systems are rendered unusable [14]. Moreover, the Mosan concept is based on the credo that anything that improves life should also protect and improve the environment. Therefore, creating systems that have a regenerative effect on the ecosystem is a core part of its operation. Mosan puts a strong focus on education, awareness raising, and local capacity building, which are crucial elements in ensuring the solution's adoption and sustainability in the long term.

\section{Operating Context in Guatemala}

Guatemala, the most populous country in Central America with its 17 million inhabitants, has among the worst access to sanitation in Latin America. Estimates indicate that $35 \%$ of the population, i.e., 6 million people, do not even have access to a basic sanitation service, going up to $49 \%$ in rural areas [23]. The lack of water and sanitation affects especially the rural population, with $47 \%$ of the low-income families lacking basic hygiene with water and soap [24]. Besides, more than 7 million people do not have access to safely managed drinking water [4].

In the lake basin of Lake Atitlán, where Mosan currently operates, about 250 thousand individuals live in 18 municipalities, of which more than $95 \%$ are indigenous and belong to different Mayan ethnic groups [25] (Fig. 2). An important problem for the communities living

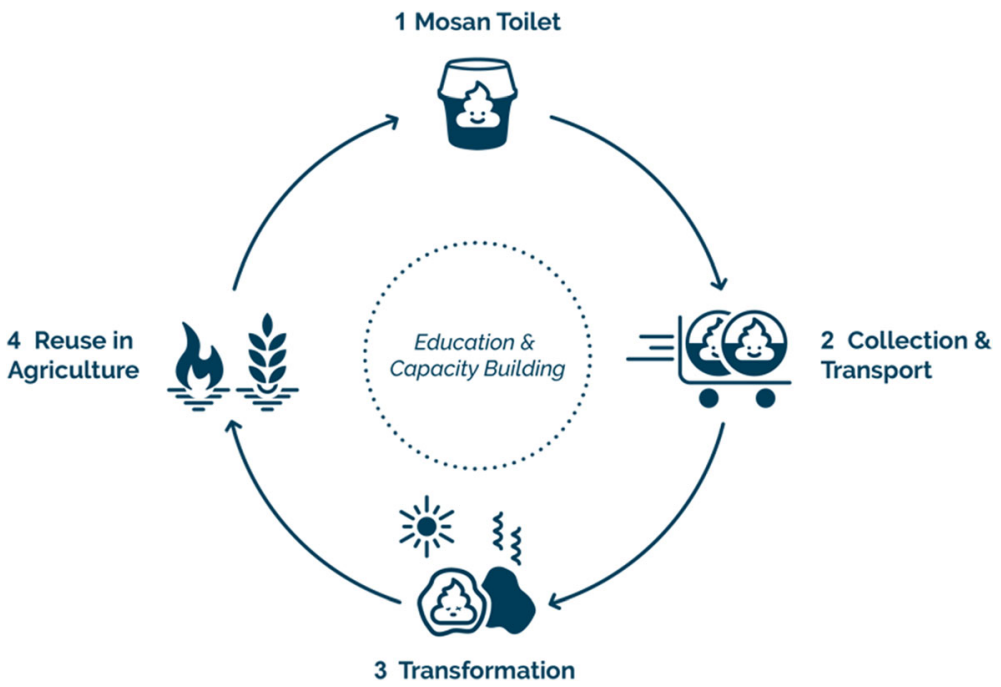

Fig. 1 Illustration of the circular Mosan system [Source: Mosan. Reproduced with author's permission.] 


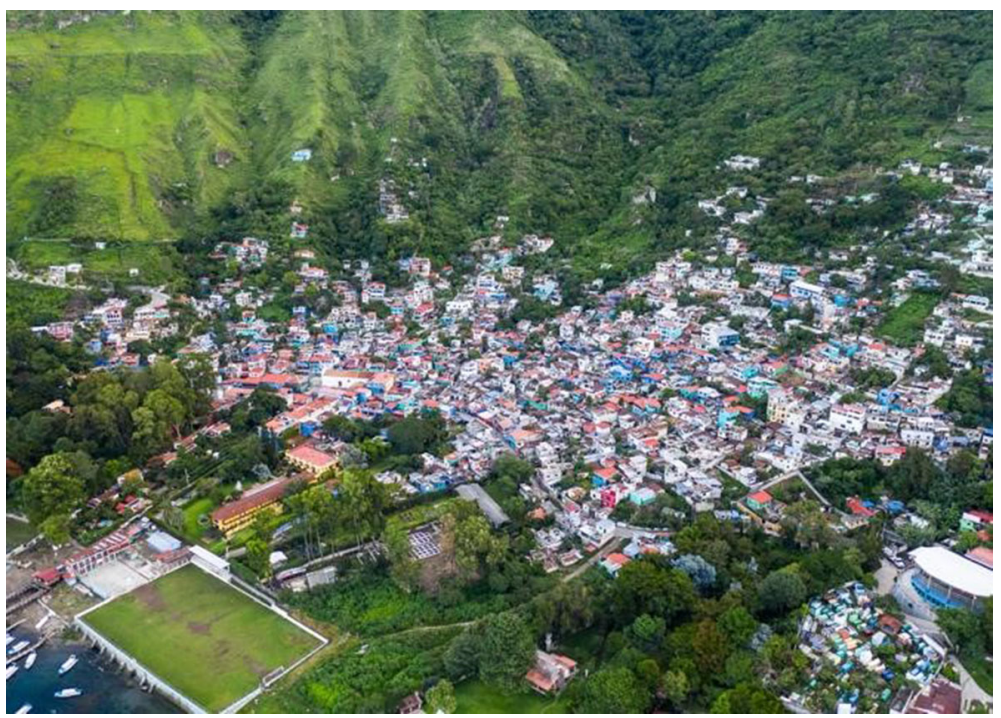

Fig. 2 Santa Catarina Palopó at Lake Atitlán. [Source: Mosan. Reproduced with author’s permission.]

around the lake is water pollution, due to improper waste disposal, indiscriminate use of agrochemicals in the soil and untreated or inefficiently treated wastewater [25].

With a poverty rate of $81 \%$ and an extreme poverty rate of $40 \%$, providing affordable improved sanitation in the region remains a challenge [25]. Of the 71,438 households in the basin, $24 \%$ are connected to the sewerage system, $20 \%$ have a septic tank, while the solution for the remaining nearly 40,000 families rests in latrines or no solution at all [25]. Both septic tanks and latrines are challenging to empty due to the terrain, narrowness, and steepness of the alleys, preventing access to vacuum trucks, which are not common in the region. Of the families that opted for Mosan's solution, $50 \%$ did so because their septic tank was full and lacked the financial means to empty it or build a new one.

Only $21 \%$ of the wastewater generated in the region is treated in the few operational WWTPs. This leads to the eutrophication of the lake water and a high level of fecal coliforms, resulting in numerous cases of illnesses transmitted via water or food, affecting over $30 \%$ of children [25, 26]. Moreover, only one out of over twelve plants is confirmed to be in compliance with all the regulations, the rest releasing effluents with a high chemical and biochemical oxygen demand [27]. The inefficiency of WWTPs is caused by inadequate design, lack of knowledge of operating and maintaining the plants, elevated costs, and a lack of control over wastewater effluents $[25,26]$.

\section{The Mosan Toilet}

The Mosan toilet is an ergonomic, mobile, and light-weight in-home toilet (Fig. 3). It has been designed over 5 years through numerous improvements in order to create a long-lasting attractive product that people want to integrate in their home. The toilet is in its fourth iteration and is the result of a participatory design process that included users and stakeholders in Bangladesh, Kenya, and Guatemala. Industry collaborations allowed the optimization for large-scale production, easy shipping, stacking, and transport. The toilet is made from recyclable polyethylene. The first models were produced in 2013 and are still functional, thus 


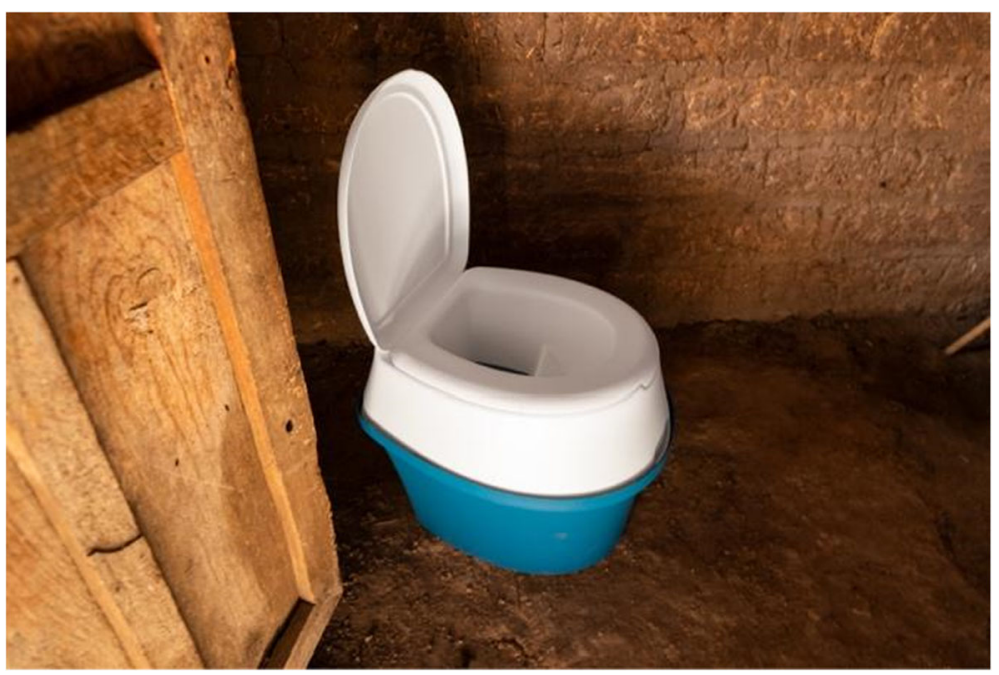

Fig. 3 Mosan toilet inside a family's home. [Source: Mosan. Reproduced with author's permission.]

allowing an estimated minimum lifespan of 8 years. The materials are fully recyclable. The Mosan toilet includes two sealable containers: one for feces, in which sawdust is used for covering to avoid smell and flies, and one for urine, having an anti-odor valve that closes after use. The separation of urine and feces is key to avoid smell and ensure an efficient transport, transformation, and reutilization of excreta.

\section{Collection and Transport}

The user brings two or three times per week the full containers to a collection point where fresh containers are provided. Containers are emptied and cleaned, and excreta are then transferred into bigger barrels that are transported to the Mosan transformation center. Currently, the transport is done by foot, but a motorized transport or a combination is possible for areas with road access. Mosan's service is illustrated in Fig. 4.

\section{Transformation and Resource Recovery}

At Mosan's transformation center, the feces mixed with sawdust are pyrolyzed into biochar. Pyrolysis is a process in which biomass is heated up at temperatures between 300 and $600{ }^{\circ} \mathrm{C}$ without oxygen supply to carbonize into biochar, syngas, and bio-oil [28]. When setting up the transformation process, other alternatives were contemplated as well, more specifically composting, production of charcoal briquettes, or production of biogas through anaerobic digestion. These options were assessed in terms of (i) time, the more time a treatment process requires, the higher the costs and contamination risks are; (ii) space, space is limited given that rural communities are urbanizing and tend to be concentrated, with small and narrow streets; (iii) technology, the process needs to be built and operated locally and therefore not rely on high-tech components; (iv) safety, safety of operators as well as of users of the final product; and (v) nutrient recovery rate, the amount of nutrients in feces that are preserved and that could be valorized in an end-product. Pyrolysis was chosen for the Mosan case since it requires little time and space for transformation and can be done with low-tech equipment. Also, through 
1

Families use

Mosan Toilet in privacy
2

Families bring containers to the Collection Point
3

Families receive fresh containers in return
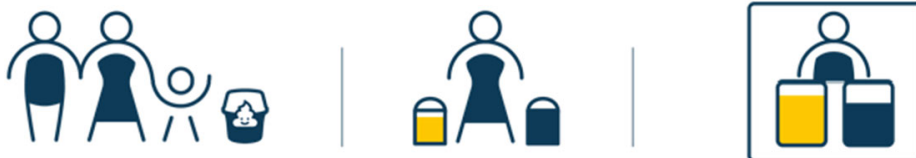

\section{4}

Mosan staff transports excreta to the Transformation Center

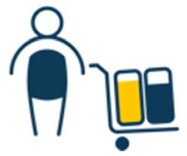

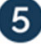

Transformation of human excreta

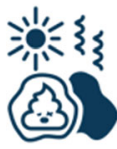

Fig. 4 Mosan service illustration. [Source: Mosan. Reproduced with author's permission.]

pyrolysis, pathogens are removed, which makes it safe to handle and decreases the contamination risk [29]. At the same time, key nutrients as phosphorus and potassium are retained in the biochar providing fertilizer or soil amendment value [30] (Fig. 5).

Biochar can improve soil properties, and it has also been recognized by the Intergovernmental Panel on Climate Change (IPCC) as a viable and scalable carbon sequestration measure [31]. Multiple studies have shown the potential of biochar to improve soil health. Increases in cation exchange and water holding capacity as well as enhanced nutrients uptake, microbial activity, and fertilizer performance have been observed with the use of biochar in soil [32-34]. The effects on the soil have direct impacts on agricultural productivity. A study in Nepal

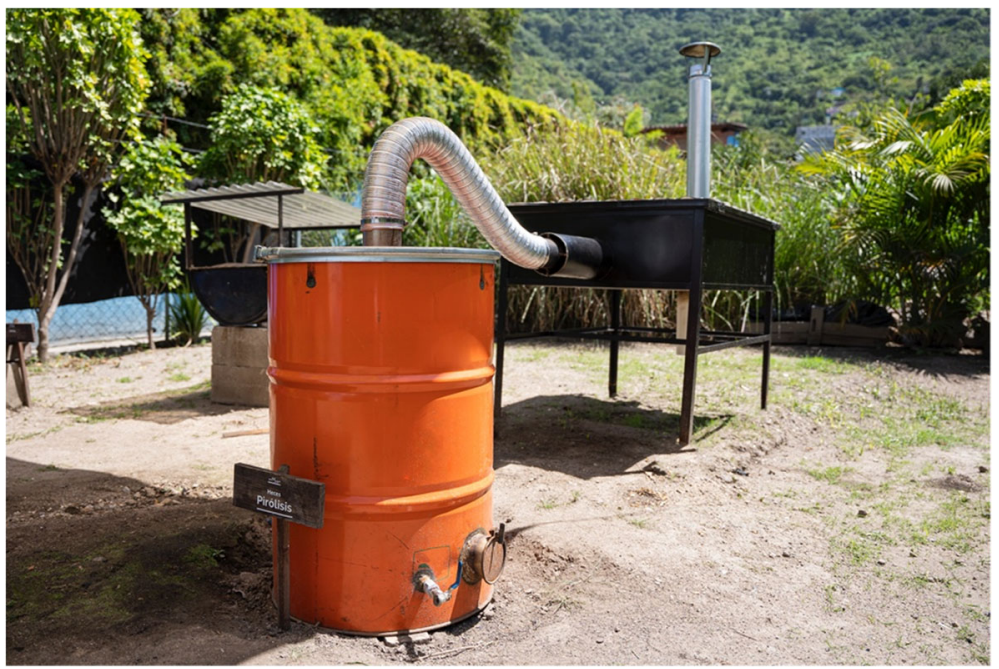

Fig. 5 Mosan's small-scale pyrolysis reactor and drying bed; pyrolysis heat is used for pre-drying of feces (2021). [Source: Mosan. Reproduced with author's permission.] 
demonstrated over $100 \%$ increase in crop yield when using cow urine-enriched biochar [35]. Enriched biochar (e.g., with urine, compost, digestate, dissolved mineral fertilizer) shows promising results given the biochar's nutrient carrier effect that ensures slow release, reduced losses, and more balanced nutrient fluxes $[35,36]$. All these features make biochar, applied alone, or enriched, attractive for use in agriculture.

The urine is currently collected and precipitated with magnesium oxide into struvite, a phosphate mineral. While this process was chosen mainly because it is a simple to build process, the struvite is not a complete fertilizer as it contains low values of nitrogen and no potassium [33]. Since urine is particularly high in plant-available nitrogen, treatment technologies that show increased nitrogen retention rates such as alkaline dehydration are being explored [37-39].

\section{Environmental Impact}

Through its operation, the Mosan system has the potential to contribute to climate change mitigation through the prevention of methane emissions by safely containing excreta. To quantify the climate impact of CBS, the Container-Based Sanitation Alliance (CBSA) supported by Water Supply and Sanitation Collaborative Council (WSSCC) has undergone a study based on four CBS operations. Results indicated that the CBS systems save between 80 and $210 \mathrm{~kg} \mathrm{CO}$ eq/person/year. The savings were calculated against existing OSS systems such as pit latrines and septic tanks $[15,16]$. Savings from the use of excreta-derived products such as biogas or briquettes were also included. Given that the highest population growth is in low- and middle-income countries, where also the highest rate of growth of OSS is, it can be expected that the future demand of sanitation will be covered with OSS [4]. Therefore, this may lead to increases in methane emissions that may undermine climate change mitigation efforts [15]. Plus, methane has an 80 times higher greenhouse warming potential compared to $\mathrm{CO}_{2}$ on a 20 -year timeframe (GWP20); thus, it has an important impact on climate change particularly in the near term. The latest IPCC report (Sixth Assessment Report) highlights the opportunity of cutting methane emissions to provide short-term climate change relief [40].

The other climate change mitigation potential of Mosan lies in the use of biochar in the soil as a $\mathrm{CO}_{2}$ sequestration measure. Biochar is primarily made of very stable organic carbon, which, when applied to soil, can be locked up for several centuries [31]. When anaerobic conditions are present, which is most of the time the case in OSS, organic matter decomposition leads to methane emissions [17, 41]. By using pyrolysis and applying biochar to soil, up to $50 \%$ of the carbon that would otherwise be released as methane can be locked in, while the rest will be released by the use of the biofuel created [42]. A visual representation of the carbon cycle with and without pyrolysis can be seen in Fig. 6. In addition to storing carbon, biochar has been shown to improve the soil quality and if enriched can potentially be a replacement to synthetic fertilizers, which would lead to additional $\mathrm{CO}_{2}$ savings $[32,35,36]$.

The environmental impact of Mosan goes beyond its climate change mitigation potential into reducing water usage and effectively limiting excreta contamination in people's houses, water bodies, and community environments [9].

\section{Participatory and Community-Led Service}

Through involving numerous local actors, community leaders, users, and prospects, Mosan facilitates participation, following a multi-sector, multi-actor approach. The ultimate goal is for 

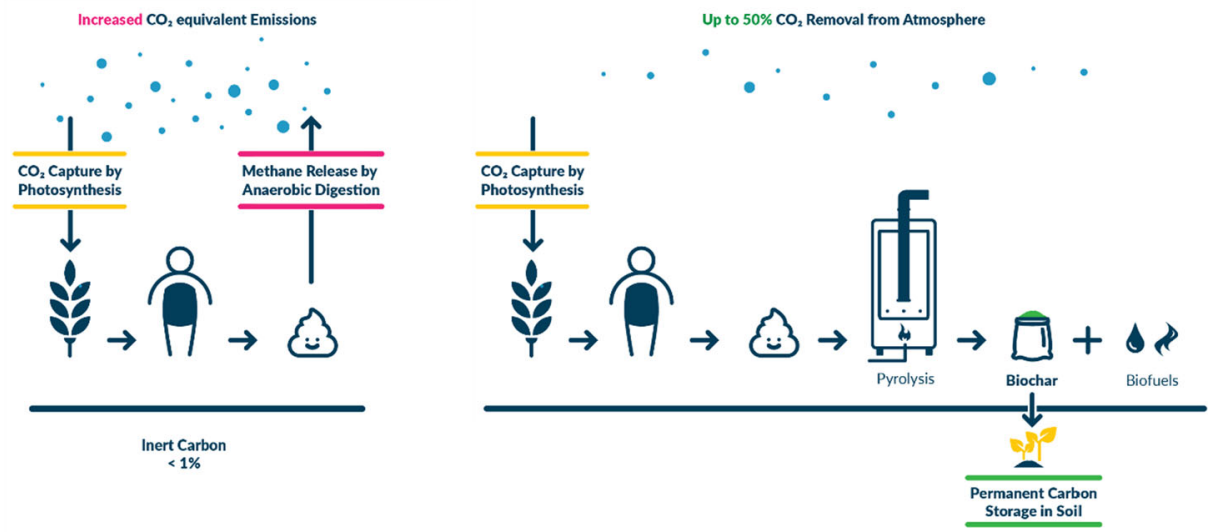

Fig. 6 Carbon cycle with anaerobic digestion (left) and with pyrolysis (right). [Source: Mosan. Reproduced with author's permission.]

the service to be fully community-led. In the Mosan case, a community is defined as a group that shares certain social and cultural bonds, usually based on a geographic location. Building a wide range of skills and local capacities is critical for Mosan to be a sanitation service facilitator, whose role is guiding and supporting a service led and operated by community representatives. Skills are not limited to technology or operative knowledge but also include participatory project management, community building, stakeholder coordination, and conflict resolution. Developing inclusive implementation strategies is important to ensure the adaptability and sustainability of the system. Stakeholder participation throughout the design process creates shared ownership, buy-in, and responsibility and supports the co-creation of locally and culturally feasible solutions. The goal is to go a step further and cultivate leadership from the community in managing, maintaining, and growing the service after the design process. The community-led Mosan sanitation services are built through the participatory approach and by providing agency to the community to have decision-power and leadership in the long-term. The aspect of participation is further discussed in the section "Mosan's Approach to Participatory Design”.

\section{Overview of the Business Model}

Mosan's business model is centered around several markets: (i) the market of "sanitation as a service" offered to municipalities, NGOs, or other institutions supporting local communities. This is globally a rather new approach and certainly not common in the indigenous context. Most commonly, access to sanitation is either the responsibility of individual households or of the municipalities in charge of building centralized systems; (ii) the market of "sanitation as a service" is based on a subscription model to end-users. In the Mosan case, users are lowincome families that use the service, for which they pay a monthly fee. In Mosan's current service location in the village Santa Catarina Palopó in Guatemala, the monthly fee was set at GTQ 35 but may vary depending on the economic situation in different areas and the user's willingness to pay. This is equivalent to roughly USD 5, which is $1.3 \%$ of a household income, assuming one adult in the household is earning the annual gross national income [43]. This is well below the 3-5\% affordability benchmark for water, sanitation, and hygiene defined by the 
World Bank [18]. The fee is meant to ensure engagement and commitment from the user's side and increase the perceived value of the service at an affordable price. By joining Mosan, the users receive the Mosan toilet, benefit from container exchange at collection points, and are regularly invited to educational events and capacity building workshops; (iii) the market of commercializing agricultural products such as human excreta-derived soil amendments. The commercialization of biochar as a revenue stream can progressively become more significant and cross-subsidize parts of the sanitation service operational costs. Mosan's efforts are currently focused on developing an enriched biochar-based fertilizer that can reduce the amount of synthetic fertilizer needed by proposing an organic alternative with high nutrient concentrations. The organic fertilizer market consists mainly of low nutrient alternatives that require high application rates [44]. This affects its market value as well as its usability.

Urine transformation and its use as an end-product are a challenge for Mosan and CBS systems at large. While there is substantial research on various technologies available, none of them has been integrated into CBS services [9].

Mosan's business model is constantly evolving and being reshaped to respond to various market drivers and opportunities. Other revenue streams such as carbon credit commercialization are being investigated to demonstrate and leverage on Mosan's climate impact. While a standardized carbon accounting methodology for carbon credit certification for such projects does not exist yet, several organizations are currently researching this opportunity [45].

\section{Scaling and Replication}

Mosan was designed as a community-scale, decentralized, replicable solution. In the longterm, Mosan's strategy is to scale via social franchising, seeking to enable community-led services, thus maximizing its social and environmental impact. The replication via franchising would allow Mosan to share responsibilities with the franchisee, who would learn how to operate the sanitation service on a daily basis, while Mosan can focus on development and innovation. Mosan would provide a start-up package, training, and support in setting up the service. Franchisees would go through intensive training and remain in close relationship with Mosan. While the technological and operational aspect of Mosan can be more easily replicated, the participatory design approach needs to be adapted based on the level of awareness and interest in participation in each community.

\section{Managing Costs}

As with most CBS services, Mosan is currently not cost recovering and is relying on a mix of public, philanthropic, and private funding sources [9, 14].

Mosan is envisioning a design-build-operate (DBO) model, through which the sanitation service offtaker (municipality, $\mathrm{NGO}$, etc.) together with other direct revenues (from users, agricultural products, and carbon credits) covers the operational costs of the service, while the capital investment is covered by investors, donors, and reinvested profits. Given the modularity, small-scale, and use of optimized, low-cost technologies, capital costs are kept low, on an annualized basis staying below $10 \%$ of the total costs.

As it has been shown in previous modelling exercises [19], in a CBS, the operation scale does make a significant difference on the unit economics. Assuming only small variations in indirect costs, the unit economics are substantially improved for services over 200 households, 
as can be seen in Fig. 7. For services over 1,000 units, the monthly unit cost can be as low as USD 24, with USD 14 in direct operating expenses.

This is in line with other CBS comparative analyses [46]. On a per year basis, the unit cost for services of 1,000 units would amount to USD 300, which is between $30 \%$ to just over $60 \%$ of the average costs of a sewerage system, depending on the type of system. This estimation was done using the Climate and Cost in Urban Sanitation (CACTUS) data. Per unit cost optimization when scaling is derived from the dilution of indirect costs (overheads) and the optimization of the direct operating expenses.

Direct operating costs are largely dominated by labor costs. This means that scaling CBS would translate in job creation in low-income communities and increased economic activity [18]. This also means that direct operating costs can be optimized with scale and the professionalization of the operation. Given that Mosan operates across the entire value chain, multiple opportunities of efficiency gains have been identified. Sales costs can be reduced if partnerships with municipalities are secured, collection can be optimized by employing vehicles as on-schedule collection points, transportation can be improved by route optimization, and excreta transformation can be optimized by using semi-continuous pyrolysis reactor models. All these efficiency gains are reflected in the cost optimization presented in Fig. 7. A first step currently in progress is optimizing the pyrolysis reactor and developing further models to fit different service sizes. Smaller batch-style reactor models are ideal for services up to 100 families, whereas semi-continuous reactor models would be implemented in services with more than 100 families.

The development of a market for human feces-derived fertilizers and the activation of alternative revenue streams as carbon credit sales would certainly increase the resilience of Mosan to risks associated with contracts with sanitation service offtakers. The size of the remaining funding gap to be covered by the sanitation service offtaker depends on how these revenues would materialize. While currently most carbon credits on the voluntary carbon market trade at prices below $10 \mathrm{USD} / \mathrm{CO}_{2}$ tonne, studies have shown that in order to create a credible emission reduction claim the market price should increase up to 100 USD by 2030 [47]. Furthermore, some companies practice internal carbon pricing of over USD $100 / \mathrm{CO}_{2}$ tonne to drive innovation and investment in the space [48]. The market of fertilizers and soil

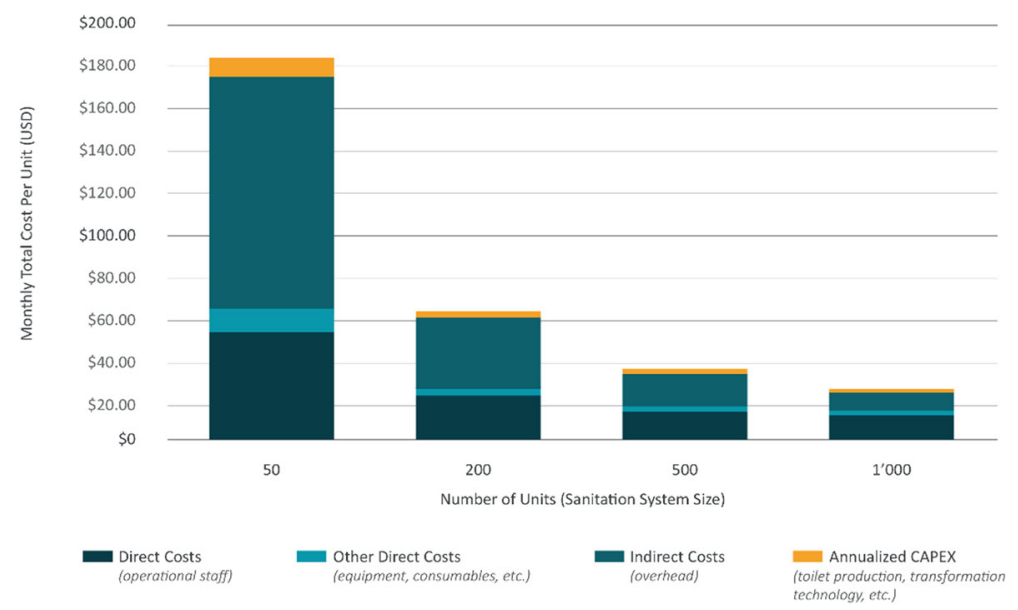

Fig. 7 Total projected service cost per unit per month for different service sizes. [Source: Mosan. Reproduced with author's permission.] 
amendments is also very diverse. While compost might sell at USD 400 per tonne [14], valueadded enriched biochar products for niche markets can be priced much higher at over USD 6,000 per tonne [49]. A $100 \%$ operational cost recovery could be achieved commercially if the maximum possible revenue from these two sources is assumed, as shown in Fig. 8. However, in the short term, there will most likely be a gap that needs to be secured most likely through public contracts or subsidies [14, 19, 20].

\section{Mosan's Approach to Participatory Design}

As technological solutions alone will not bring the shift in communities needed to tackle complex challenges, an essential part of Mosan's mission is to enable local populations to participate in the innovation process, thus creating shared ownership and responsibility over the sanitation solution and fostering creativity and problem-solving capacities. Through capacity and knowledge building, people gain a sense of confidence in their own capabilities, which contributes to community empowerment. Co-creation as an approach to participatory design goes beyond simply designing products or services for users: "We are designing for the future experiences of people, communities and cultures" [50].

The Mosan solution has always been shaped by design as a discipline. From the design of technologies, user experiences, services, or awareness campaigns in different cultures, design principles are deeply embedded in the Mosan solution. Those principles continue to fuel the solution and its implementation today. Design in this context is considered a praxis, an approach with different explorative and qualitative methods, which always focuses on people. Research is conducted through design in a non-linear and iterative process [51]. Mosan in this process has to constantly switch roles to respond to changing situations, from planning and researching, to making and form-giving, to active facilitation and to passive observation. Findings have to be visualized and reintegrated into the design process to inform further iterations [52].

The participatory design applied by Mosan is a collaborative approach in which Mosan members and other stakeholders work together with members of the impacted community to design appropriate solutions [53]. It can also be defined as a value-centered design approach

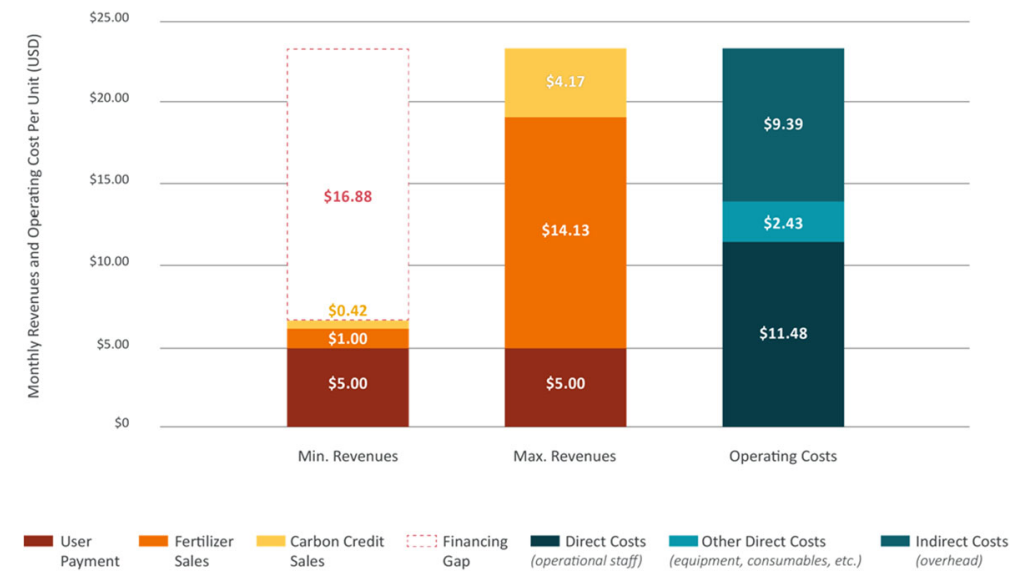

Fig. 8 Projected monthly operating costs per unit vs. monthly revenues per unit (for a service size of 1'000 units). [Source: Mosan. Reproduced with author's permission.] 
because of its commitment to democratic and collective shaping of the future [54]. To facilitate participatory processes, it is important to recognize the differences in types of knowledge and power dynamics existing among people and groups. Participatory design shows and challenges those power structures to create a more democratic process that includes those who are usually marginalized and excluded from decision-making [55]. The implementation of the Mosan system, especially in indigenous communities, asks for a socially conscious and inclusive approach that allows people's voices to be heard. In Guatemala, social exclusion, racism, and dispossession affect most indigenous groups. Their representation in politics displays this exclusion with only $10 \%$ of all members elected to the congress of the republic being indigenous, though based on the latest census, $44 \%$ of the population identify themselves as such [56].

To achieve the goal of inclusive decision-making, participatory design provides a space where the principles of power sharing, knowledge exchange, and representation of the various actors can be realized [57]. "As an approach that seeks to interrogate prevailing power structures, challenge dominant narratives, and address existing social inequalities, participatory design can serve a mission of decolonization" [57].

Participatory approaches provide the foundation for innovation at Mosan and have shown to bring innovative results when conducted strategically. Mosan's participatory approach starts by identifying key partners for the process. In order to do this, an understanding of the local ecosystem and its actors is needed. The "local innovation ecosystem model" by Elizabeth Hoffecker at MIT D-Lab is a practical framework that has been used to map the system of actors, their roles, resources, and the enabling environment [58]. Besides community members, leaders, user families, and members of local women groups, Mosan invites local authorities, representatives from the private sector such as health clinics, actors from research and academia such as national and international university partners, students, NGOs, and funding partners to participate.

The participation of diverse stakeholders in Mosan's processes offers numerous benefits. It enables the adaptability of the Mosan sanitation system to the local context. Local actors are being considered experts and bring a vast set of knowledge about the sociocultural and problem domain, also referred to as basic knowledge, while Mosan brings process knowledge, to facilitate the participation and design knowledge to integrate products and services, e.g., suitable technologies and their adjustments [52]. The participation leads to an increased awareness about the root problems of sanitation, allowing people to understand how it affects them and their families and thus increasing their openness to innovation. This awareness can lead to behavior change, especially for hygiene practices [59]. Participation also builds relationships among stakeholders and Mosan, building trust and solidarity and leading to social cohesion and a sense of community. Stakeholder participation in the design process also increases the local capacities for creativity and problem solving [60]. Overall, the participation of the community and local stakeholders leads to a sense of co-ownership, buy-in, and higher rates of adoption of the Mosan solution [61]. These are important building blocks of Mosan's community-led sanitation service.

To successfully guide the process and collaborate with marginalized communities, Mosan does need to bring sufficient pre-understanding of the sociocultural context. To ensure this, the Mosan team consists of local and national members with awareness of the working context. Mosan's participation strategy has evolved from several years of facilitation and practice in the field and has been applied to develop the first Mosan service in Guatemala [62]. The approach is continuously reflected upon and being improved. Since each community is different, with its 
own culture, traditions, and environmental context, adaptations of the Mosan system with the participation of local actors are indispensable for the replication to further locations.

\section{Types of Participation}

Mosan's participatory approach to design refers to a larger process and vision where community members and stakeholders are considered collaborators and a multi-directional exchange of knowledge occurs [52]. Based on Mosan's experience, participation does not need to be continuous but may happen intermittently, maintaining and deepening relationships among Mosan team members, local actors, and community members.

There are different types of participation characterized by the methods used to engage stakeholders, their roles in the specific phase of the design process, and their involvement in decision-making [60]. The types of participation used by Mosan are inclusion, collaboration, co-creation, and empowerment. This spectrum is inspired by the design participation ladder by Hussain and can be visualized in Fig. 9 [60]. The types of participation on the lower end are characterized with low levels of participation and low influence of participants on decisionmaking (inclusion), moving towards high (co-creation) and very high levels of participation and decision-making power (empowerment).

On the lower end of the spectrum, in inclusion, different ethnographic methods such as interviews or observation are used. Those approaches are one-directional and have the main purpose to gather information and feedback. Participants have no active influence on the design of the solution but participate with their ideas and opinions. In collaboration, participants may influence some decision-making, but Mosan remains in lead of the process overall. In Mosan's co-creation approach, participants are considered partners that share more of the decision-making power as well as the responsibility over the planning and implementation of the creative process. In empowerment, participants become the leaders of the process, while Mosan provides support and input as needed.

The term co-creation is widely used and became a trend word in brand development and marketing [50]. Already in 2007, Sanders and Stappers discussed how opinions vary when it comes to co-creation, about who should be involved, when, and in what role [50]. Still today, the term lacks a clear definition. In Mosan's experience and practice, co-creation is an advanced form of participation. Co-creation is not a single event or workshop where participants provide their opinions, it's an iterative process that challenges all actors to share control and define joint solutions. The participation of community members and other stakeholders in the decision-making and design process requires thorough preparation and capacity building. Co-creation processes are therefore more time- and cost-intensive [52]. Especially when applied during early phases of the design process when problems are defined and a direction

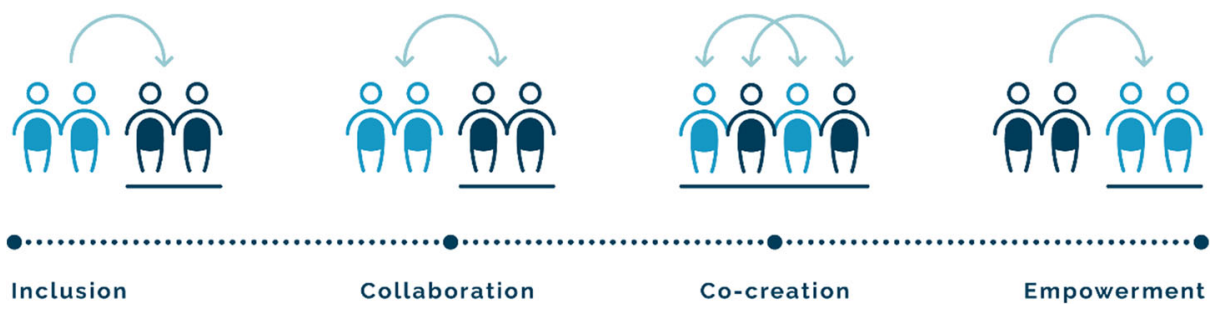

Fig. 9 Participation spectrum showing the relationship between stakeholders (light blue) and Mosan (dark blue), highlighting who is having the lead (underlined). [Source: Mosan. Reproduced with author's permission.] 
is chosen, co-creation allows participants to gain ownership over the process [52]. As with all participatory strategies used, the sociocultural context asks Mosan to adapt methods and activities. Guatemala is the most collectivistic culture in the world, according to Hofstede's "Dimensions of National Cultures," meaning that people prefer to form collective opinions and goals [63]. Planning extra time and creating space for the collective decision-making and group discussions among participants during co-creation processes have increased the success of Mosan's interventions.

As for empowerment, it is an ongoing process in which an individual identifies or affirms their own ability to affect their reality, instead of falsely assuming that others give the "empowerment" to them [64]. Empowerment can also be explained as "design by the user," one of the three types of participatory design practiced by MIT D-Lab, an interdisciplinary program at the Massachusetts Institute of Technology, Mosan is collaborating with [65]. In contrast to designing "for" or "with" users, "design by" provides the basic principles of design, access to the tools and resources, allowing users to design their own solutions [66].

It is important to note that different types of participation may be more appropriate and effective in different phases of the process and that more than one type might be used. Mosan's experience has shown that higher levels of participation might not always be more effective. To define the appropriate participation for a particular engagement, some aspects need to be defined: the goals of participation and what constraints and barriers may be faced. When assessing the design and implementation process of the Mosan system, different types of participation with different actors can be observed in all phases, from the (1) assessment of a new service location, discovery of the local context, and administrative preparations, to (2) project definition, (3) development and design, (4) implementation, and later to the (5) operation, maintenance, and growth of the system. The implementation process is repeated when replicating the service to further communities.

Participation approaches used in the initial phases (1-2) of the Mosan system development are mainly aimed at learning and researching in order to better understand the local context, users, and involved stakeholders. Participation approaches in the development, design, and implementation phases (3-4) of a Mosan system are mainly aimed at building capacity in the local population and participating stakeholders to express their ideas and take on an active role to realize them. This goal of building capacity is not limited to the design and implementation phases. Most goals are cross-cutting throughout the process but are prioritized in some phases. Other such cross-cutting goals are information gathering, relationship and trust building, community building, and awareness creation.

In 2020, Mosan did a needs assessment in Santa Catarina Palopó, part of which households have been visited and interviewed. The two interviewers were users of the Mosan service and members of the local community. The actual process and strategy for gathering information were co-created and planned with them. The two women had been Mosan users since the beginning of the pilot in 2018. A trustful relationship was already established.

Both women were invited to brainstorm strategies to conduct the needs assessment. Goals were commonly defined. The women argued that visiting people at home would be the most comfortable setting to discuss taboo topics such as sanitation. A needs assessment strategy was designed collaboratively and afterwards tested within the Mosan team. As part of a role play exercise, Mosan members and the women tested and enacted possible scenarios that could happen during house visits, for example, people not being interested to talk or people having little time. The role play allowed the group to prepare and iterate the approach. For two weeks, the women were conducting the home visits on their own, meeting community members in 
their roles of Mosan users themselves. Frequent meetings and check-ins with the Mosan team enabled regular evaluation and improvements throughout the process, while during home visits, the two women had full decision power, responsibility, and ownership over the process (Fig. 10).

The information gathering approach proved to be successful as 230 families participated and shared information. The two women contributed with cultural translations, providing a deeper understanding of the results, and helped Mosan understand user's daily life dynamics, motivations, and struggles, which are aspects that otherwise would have been difficult to recognize. The approach included various types of participation from collaboration and cocreation, up to empowerment, where the women took the full lead in conducting the house visits and tackling challenges on the go. Mosan further invested in professional marketing training for the two women and Mosan team members, increasing the capacity for future cocreation and collaboration.

Regarding the quality of participation, there are important aspects which contribute significantly to the success of participatory events and efforts. One of these key aspects, often overlooked, is the actual preparation required for participation. Within preparation, two elements that Mosan has found to be essential are capacity building and mindsets building of stakeholders.

\section{Participatory Design Mindsets}

Decades of research have shown that mindsets, as the thoughts, beliefs, and assumptions that influence how we respond to situations, have the ability to influence learning, achievement, and motivation, which in turn branch out in numerous traits and attitudes that alter behaviors [67]. Mindsets are paramount in laying the foundation for participatory design and are the real agents of change that create lasting community transformation.

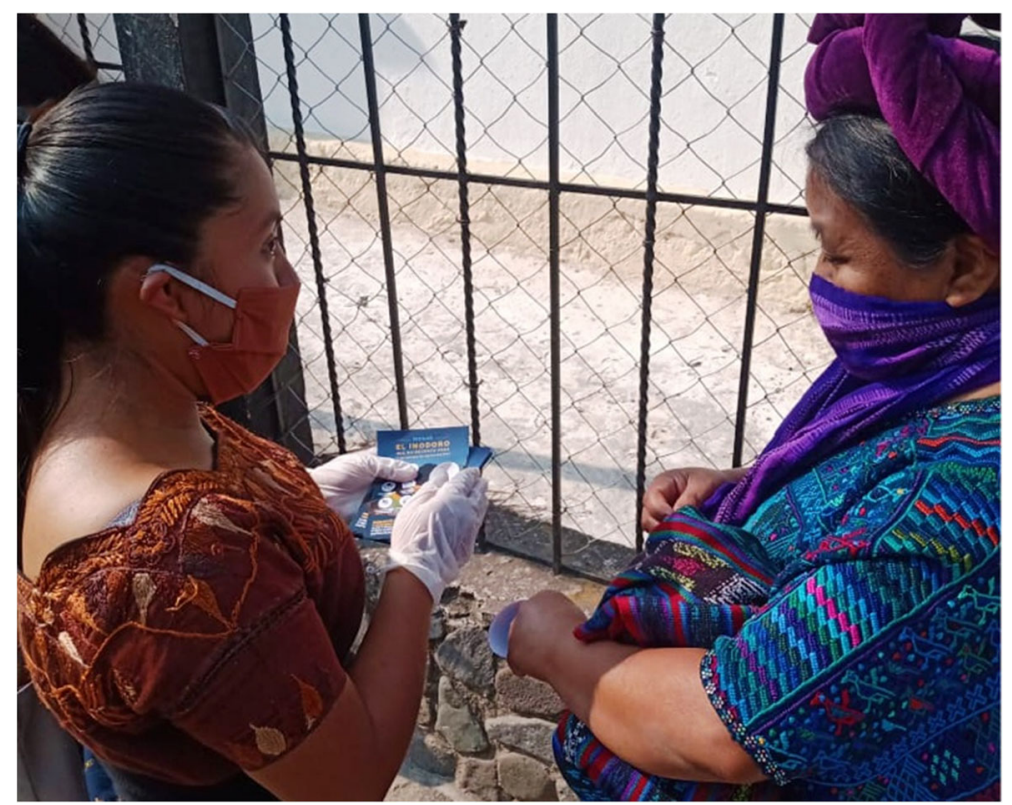

Fig. 10 A Mosan user is gathering information and sharing her experience with neighbors (2020). [Source: Mosan. Reproduced with author's permission.] 
There are specific mindsets embodied and promoted at Mosan that reflect the culture of the organization: having an inclusion mindset is about inviting diversity and enabling diverse approaches. Curiosity is about having a beginner's mind and digging for root causes. Iteration is about having an attitude of "try it, learn, and keep improving." Optimism is about having a feeling of abundance, being resourceful, and solution-driven. Empathy is about honoring everyone's perspectives. Flexibility is about keeping an open mind, being agile, and embracing ambiguity. Finally, having a connection mindset is about connecting as humans first and as collaborators later, listening, showing respect, and building relationships.

Practicing and teaching these mindsets have allowed Mosan to build participation environments in which everyone feels encouraged to learn and contribute. By first experiencing mindsets consciously to then embodying them intentionally, the Mosan team brings these mindsets into activities and interactions.

Aside from those participatory design mindsets, there are additional mindsets that need to be fostered in order to build circular systems. When designing for circularity, the whole lifecycle of products and materials needs to be considered. This requires a shift from a throwaway mindset to a reuse and reintegration one, building on one's business acumen to identify opportunities to add value to seemingly unusable materials.

Mindsets have a direct effect on the stakeholder's capacity to participate, which is a key contributing factor to the quality of participation, together with the design environment and the chosen activities [52].

Mosan developed an activity that promotes handwashing with soap. The activity builds creative capacities and establishes certain mindsets among participants while providing an immediate solution to a relevant household challenge observed in the community. Handwashing is a critical step to tackle disease spreading and improve health and hygiene. In rural communities in Guatemala, a sink as part of a bathroom is not common. Piped water supply is not constant, forcing people to store water in buckets and cooking pots. The handwashing skill building activity was designed to strengthen several capacities and mindsets: it teaches participants to build their own simple watersaving handwashing station made from recycled materials (curiosity, optimism, and reuse mindset), it brings people together for a common learning activity (connection, inclusion mindset), and it promotes handwashing in a playful way (curiosity mindset), encouraging making, prototyping, and testing the device until it functions appropriately (iteration mindset). The activity is conducted on a public space, drawing passers-by to try it out or join spontaneously, thus promoting handwashing to a wider audience (curiosity and flexibility mindset) and strengthening Mosan's position as an active stakeholder in the community. The activity is facilitated around tables in an open space environment, which supports collaboration on eye-level and allows the inclusion of everyone. At the end of the activity, participants take their own handwashing station home, which acts as a reminder of the importance of proper hygiene as well as their newly acquired skills and experience (Fig. 11, Fig. 12).

The activity forms part of Mosan's larger participatory approach to provide a complete sanitation solution for people. Handwashing is an integral part of it. The approach builds a community of innovators while shaping participatory design mindsets and thereby preparing participants for future co-creation. Skill builder activities are one strategy Mosan uses to prepare participatory approaches. Collaboration, co-creation. and empowerment are types with a very high level of participation that do not just happen but require strategic preparation.

\section{Methods and Tools}

Mosan as a facilitator in the process needs to make decisions when and which methods or tools for telling, making, and enacting are most appropriate and effective in each circumstance [52]. 


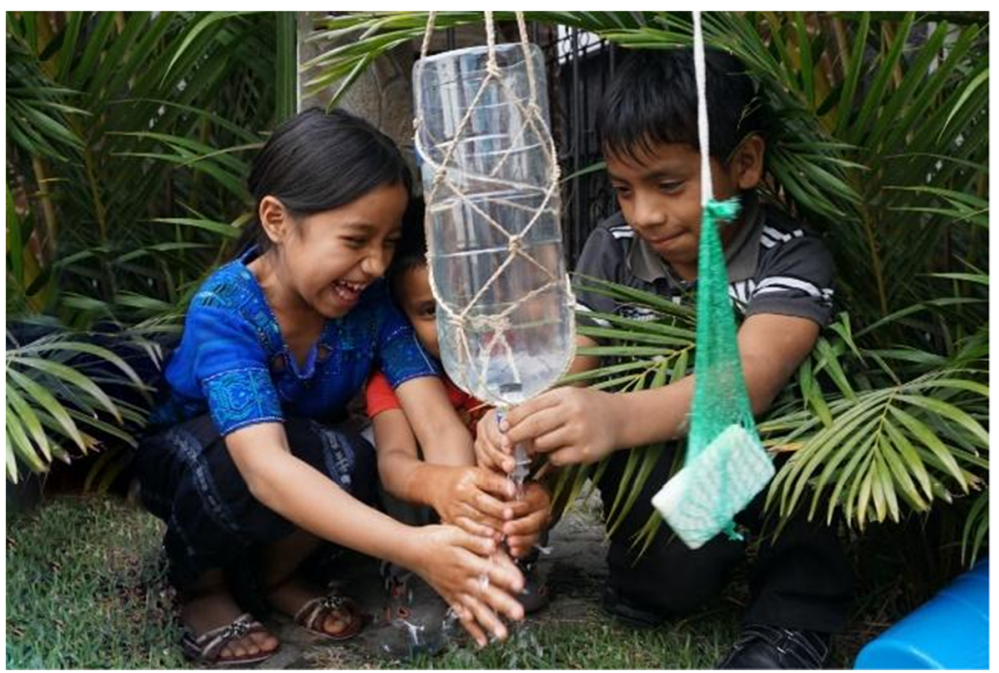

Fig. 11 Kids practicing handwashing with soap (2019). [Source: Mosan. Reproduced with author's permission.]

The distinction between making, enacting, and telling activities and their respective tools and methods allow one to prepare for participation. Activities focused on making use artifacts such as models, prototypes, collages, journey maps, storyboards, or sketches. Enacting-style activities integrate role play or testing of prototypes. When the focus is on telling, conversations, interviews, and group discussions can be used [52].

Mosan needs to constantly integrate tools to visualize observations, learnings, and new ideas from different perspectives. Visual techniques can encourage participants to plan and to act, as new ideas become tangible thus allowing further dialogue, fostering innovation and reducing the risk of misunderstanding [68].

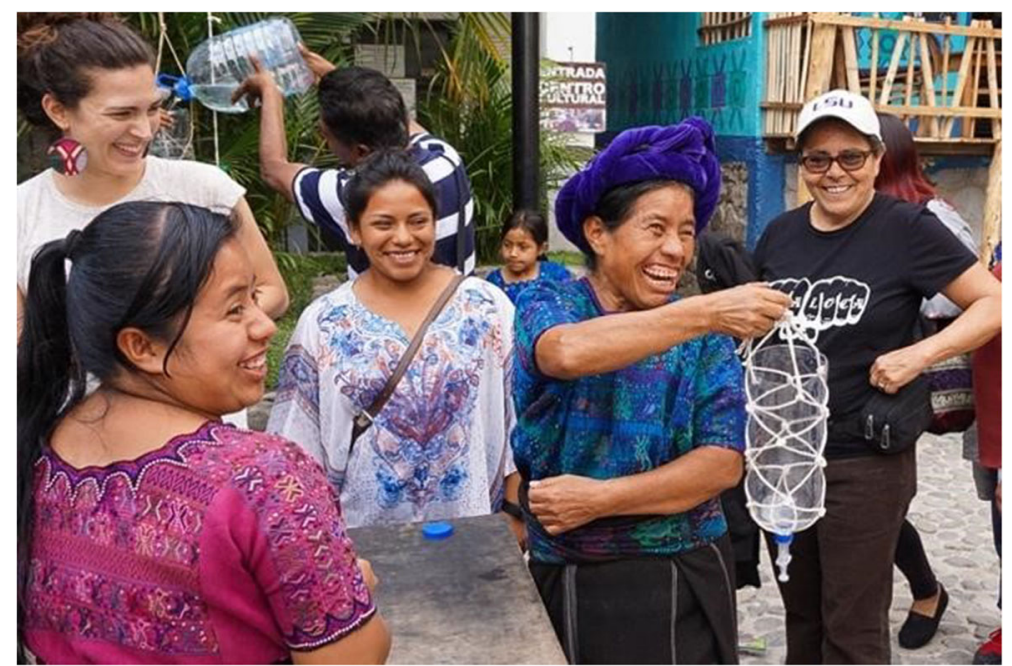

Fig. 12 Handwashing skill building activity on the central plaza in Santa Catarina Palopó (2019). [Source: Mosan. Reproduced with author's permission.] 
Choosing the activities and content strategically is important to ensure the topics are relevant for all participants. Transparency is a core value for all formats. Participants should be informed how ideas will be used and move forward, which can create trust and a sense of pride.

Creating connections and relationships between different actors forms the basis for participation. An effective way of doing this is by identifying commonalities. This can be done through various activities such as conversations or storytelling, in various settings such as house visits, events, or workshops.

A practical tool is the Storytelling Cube developed by the Guatemalan organization Link4 [69]. The tool is designed for complex collaborations when diverse groups come together, and language and cultural barriers inevitably appear. As an actor and partner in the local ecosystem, Link4 produces the tool and supports the facilitation where Mosan identifies the opportunity. The Storytelling Cube is a generative tool, meaning that participants build and customize it with their personal views and experiences as part of a workshop [70]. It allows information gathering in a non-extractive way, guiding participants in a group format to share stories. This is especially effective, given that when hearing stories, the human brain releases chemicals that trigger the human ability to connect and empathize [71]. The Storytelling Cube fosters creativity, reveals needs and priorities, and builds empathy and relationships in a playful and meaningful way [72] (Fig. 13; Fig. 14).

Relationship building is especially important when looking at the current culture where Mosan operates. Based on Erin Meyers "Culture Map" scale for trusting [73], in the Guatemalan culture, most people tend to build trust based on relationships ("personal connections") instead of based on tasks ("business-related activities"). It is not enough to offer a great product or service. Trust stems from personal relationships built over time between people.

An example of trust building with municipalities is the participation of at least one Mosan member in political gatherings and in official meetings with authorities and political groups. That representation and active participation creates legitimacy for Mosan's purpose (Fig. 15).

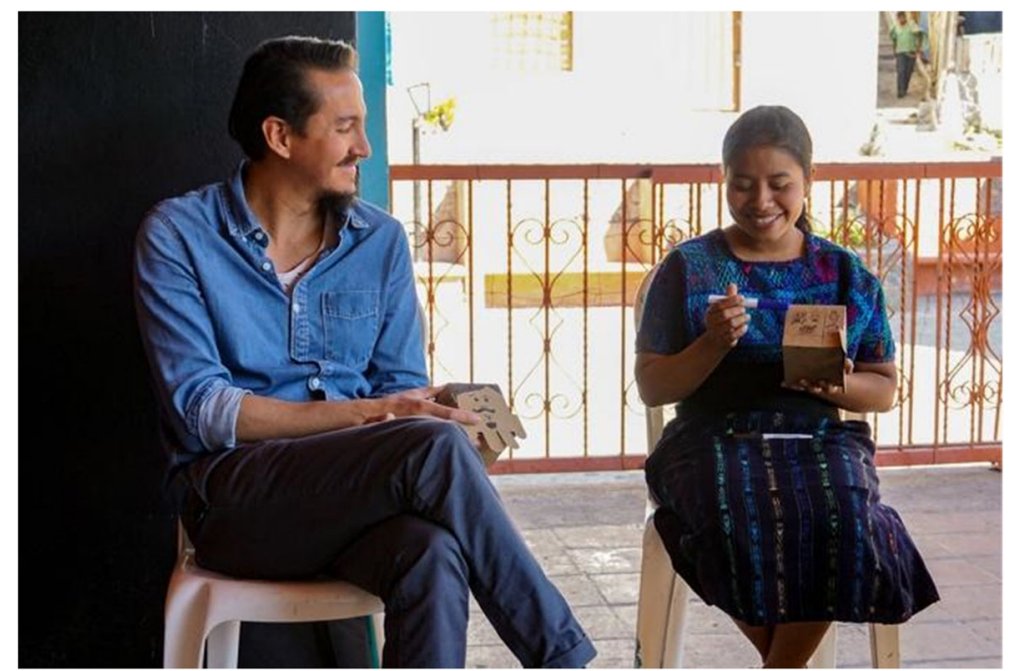

Fig. 13 Storytelling session in Santa Catarina Palopó (2018). [Source: Link4. Reproduced with author's permission.] 


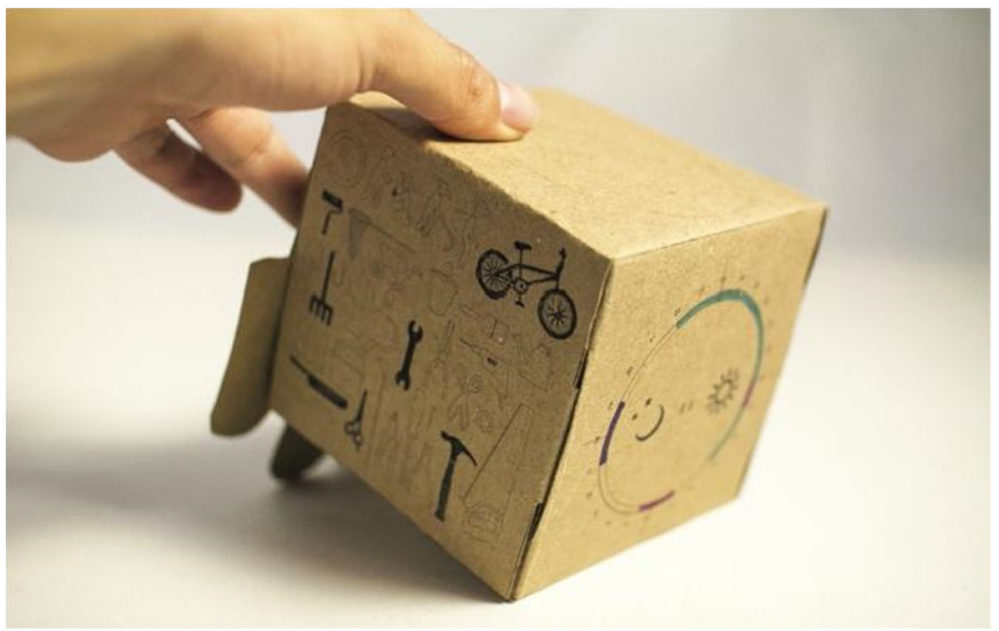

Fig. 14 “Storytelling cube.” [Source: Link4. Reproduced with author's permission.]

As part of the operational service, Mosan uses semi-central collection points as an effective way to ensure exchange of full and fresh toilet containers (Fig. 16). The first collection point was set up in the sector of the community where the pilot started in 2018. To improve the user experience at the collection point, the Mosan team entered conversations with the user families to understand their experience with this new routine in their lives. Initially, the main focus was making the process more efficient in order to reduce the waiting time. However, conversations showed that people did not mind the time spent there. The daily schedules, especially those of the women, are busy taking care of the house and children, weaving, or engaging in other types of work. Waiting at the collection point allowed them to pause for a moment and chat with each other and the Mosan staff. Shifting the focus from reducing the quantity of time spent there to improving the quality of that time led to creating a valuable service experience.

The participation of user families in the design of the collection point resulted in further group discussions, brainstorming, and creative workshops. A half-day skill building design

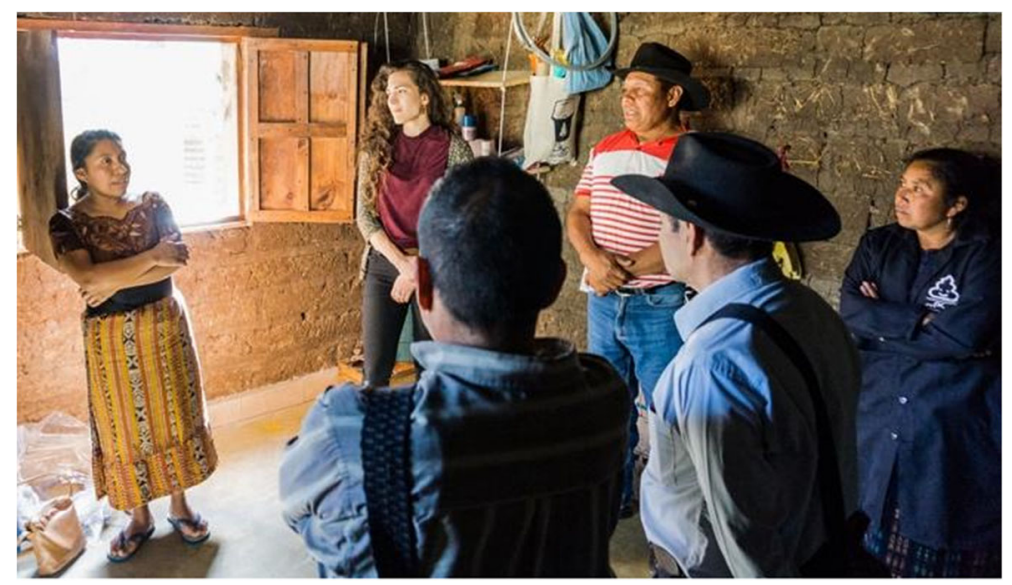

Fig. 15 A woman sharing her experience of participating in the Mosan service (2019) with the mayor and his delegates (2019). [Source: Mosan. Reproduced with author's permission.] 

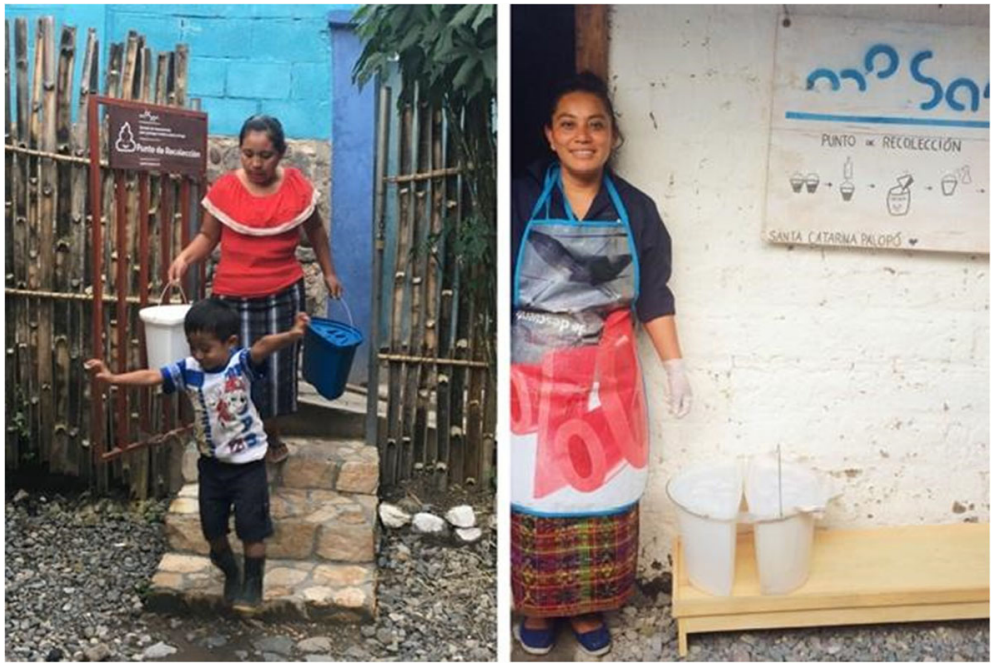

Fig. 16 The Mosan collection point (2019). [Source: Mosan. Reproduced with author's permission.]

workshop was organized to transform the space into a place for learning and exchange while making it more attractive for people to go there. A vertical garden building workshop was conceived at the collection point. Building vertical gardens taught people about herbal farming, nutrition, and the concept of a hanging irrigation system. At the same time participants would learn how to use practical tools, providing them with skills for their daily lives. The plant hangers were made from used PET bottles, incorporating the idea of recycling and upcycling, allowing the group to discuss topics of environmental contamination and waste disposal. During the workshop, the Mosan team encouraged the making, prototyping, testing, and learning from doing. People helping each other in the process revealed their participatory design mindsets (Fig. 17).

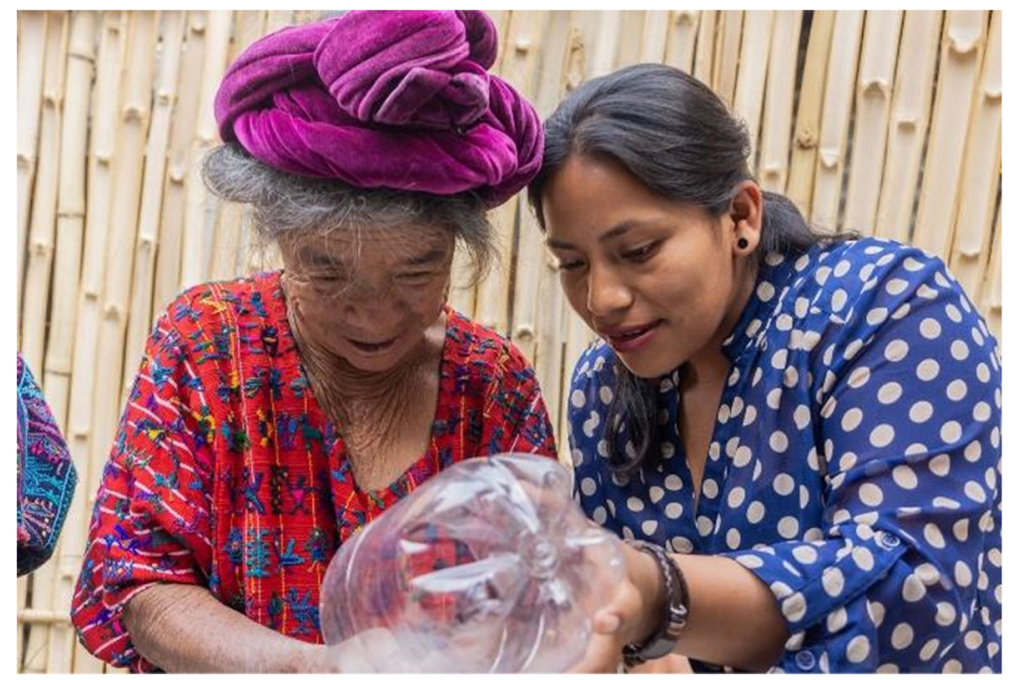

Fig. 17 A lady from Santa Catarina Palopó learning to use practical tools during the vertical garden workshop (2019). [Source: Mosan. Reproduced with author's permission.] 
The vertical garden workshop formed part of the 1-year Mosan service pilot. The participation of the user families throughout the pilot not only provided insights that informed the direct outcomes, but it also contributed to several process-related impacts of shaping a network and culture of collaboration and increasing openness towards innovation [74].

\section{Conclusion}

With just under a decade left to achieve the SDGs, universal access to water and sanitation remains a challenge. Immediate and integrated approaches that recognize and address the financial, regulatory, technical, environmental, and social challenges and opportunities that come with it are needed.

CBS provides an actionable approach for a complex challenge while incentivizing resource recovery and social inclusion. Most CBS companies are both building and serving several markets including multiple stakeholders. Working on bottom-up awareness and demand creation as well as top-down policy and regulation, CBS businesses join other approaches as CWIS in striving to change the paradigm around sanitation provision. No "one size fits all" solution but locally adapted, decentralized, community-led solutions are proposed to bridge the sanitation gap and reach the population most affected.

Recognizing the importance of integrating market-based sanitation solutions as Mosan into a legal framework that facilitates public-private partnerships is paramount to scaling these solutions. More innovative financial mechanisms that emphasize social and environmental impact over financial return and are designed to advance progress in SDG 6 could also be key in ensuring that these companies reach a scale at which they can operate sustainably.

While technology is fundamental to sanitation, alone it will not bring the change needed nor assure the success of the intervention. Mosan's participatory design approach is based on the credo that strategic participation of different actors is crucial to democratize innovation and spur inclusive, durable, and sustainable change. Mosan aims to demonstrate how technology and participatory design can work together to form a holistic solution that transforms communities.

Acknowledgements The authors would like to express their gratitude to Federico la Blasca for his contribution and support. Endless gratitude also goes to Elizabeth Hoffecker and Philippe Reymond for their valuable feedback and support throughout the process of creating this paper.

Availability of Data and Material Data sharing is not applicable to this article as no new data were created or analyzed in this study.

Code Availability Not applicable

Author Contribution All authors contributed to the study conceptualization and design and manuscript revision and read and approved the submitted version.

\section{Declarations}

Conflict of Interest The authors declare no competing interests. 
Open Access This article is licensed under a Creative Commons Attribution 4.0 International License, which permits use, sharing, adaptation, distribution and reproduction in any medium or format, as long as you give appropriate credit to the original author(s) and the source, provide a link to the Creative Commons licence, and indicate if changes were made. The images or other third party material in this article are included in the article's Creative Commons licence, unless indicated otherwise in a credit line to the material. If material is not included in the article's Creative Commons licence and your intended use is not permitted by statutory regulation or exceeds the permitted use, you will need to obtain permission directly from the copyright holder. To view a copy of this licence, visit http://creativecommons.org/licenses/by/4.0/.

\section{References}

1. McMahon A (2015) Waste management in Early Urban Southern Mesopotamia. In: Sanitation, Latrines and Intestinal Parasites in Past Populations. Ashgate, pp 19-39

2. Antoniou G, Angelakis AN (2015) Latrines and wastewater sanitation technologies in ancient Greece. In: Sanitation, Latrines and Intestinal Parasites in Past Populations. Ashgate, pp 41-68

3. Winiwarter V, Haidvogl G, Hohensinner S, Hauer F, Bürkner M (2016) The long-term evolution of urban waters and their nineteenth century transformation in European cities. A comparative environmental history. Water Hist 8:209-233. https://doi.org/10.1007/s12685-016-0172-z

4. UNICEF \& WHO: JMP. (2019). Progress on household drinking water, sanitation and hygiene 2000-2017: special focus on inequalities. Retrieved June 18, 2021, from https:/www.unicef.org/reports/progress-ondrinking-water-sanitation-and-hygiene-2019

5. Schertenleib R, Lüthi C et al (2021) A sanitation journey - principles, approaches \& tools for urban sanitation. In: SuSanA@Deutsche Gesellschaft für Internationale Zusammenarbeit (GIZ). GmbH \& Ewag - Bonn, Germany \& Dübendorf https://www.eawag.ch/en/department/sandec/

6. Lüthi C, Willetts J, Hoffmann S (2020)City-wide sanitation: the urban sustainability challenge. Front Environ Sci 8. https://doi.org/10.3389/fenvs.2020.585418

7. Tilley E, Strande L, Lüthi C, Mosler H-J, Udert KM, Gebauer H, Hering JG (2014) Looking beyond technology: an integrated approach to water, sanitation and hygiene in low income countries. Environ Sci Technol 48(17):9965-9970. https://doi.org/10.1021/es501645d

8. UNEP. (2020). Background document to UNEA-5 review report on the environmental and health effects of pesticides and fertilizers. Retrieved June 18, 2021, from https://collections.unu.edu/eserv/UNU:6451/ WorkingPaper_No6.pdf

9. Russel KC, Hughes K, Roach M, Auerbah D, Foote A, Kramer S, Briceño R (2019) Taking container-based sanitation to scale: opportunities and challenges. Front Environ Sci 7. https://doi.org/10.3389/fenvs.2019. 00190

10. Ramani SV, SadreGhazi S, Duysters G (2011) On the diffusion of toilets as bottom of the pyramid innovation: lessons from sanitation entrepreneurs. Technol Forecast Soc Chang 79(4):676-687. https:// doi.org/10.1016/j.techfore.2011.06.007

11. O’Keefe M, Lüthi C (2015) Opportunities and limits to market driven sanitation services: evidence from urban informal settlements in East Africa. Environ Urban 27(2):421-440. https://doi.org/10.1177/ 0956247815581758

12. WHO (2019) Sanitation. Retrieved June 18, 2021, from https://www.who.int/news-room/fact-sheets/detail/ sanitation

13. Christensen, C. M., \& Ojomo, E. (2019). The third answer: how market-creating innovation drives economic growth and development. Retrieved June 19, 2021, from https://www.christenseninstitute.org/ wp-content/uploads/2019/01/The-Third-Answer.pdf

14. World Bank. (2019). Evaluating the potential of container-based sanitation. Retrieved June 19, 2021 from https://openknowledge.worldbank.org/bitstream/handle/10986/31292/134664-WP-P165603-W.pdf? sequence $=1 \&$ isAllowed $=\mathrm{y}$

15. CBSA. (2020). Policy brief: supporting the shift to climate positive sanitation. Retrieved from: https://cbsa. global/wp-content/uploads/2020/11/GHG-emission-POLICY-BRIEF-13Aug2020.pdf

16. CBSA. (2020). UNC poster presentation: calculating the climate change mitigation potential of containerbased sanitation systems. Retrieved from https://cbsa.global/wp-content/uploads/2020/11/UNC-GHGposter_201019-1.pdf

17. Doorn MJ, Liles DS (October, 1999) Quantification of methane emissions and discussion of nitrous oxide, and ammonia emissions from septic tanks, latrines, and stagnant open sewers of the world. Environmental Protection Agency. EPA/600/R-99/089 (NTIS PB 2000-101018), Washington DC 
18. Ojomo, E., \& Wilcox, L. (2021, April). Making your own luck in emerging economies: six innovative strategies for creating new markets. https://www.christenseninstitute.org/wp-content/uploads/2021/04/ Making-your-own-luck.pdf

19. Ernst \& Young, Coates J, \& Gray D (n.d.). Why it's time to get behind container-based sanitation. Retrieved June 19, 2021, from https://cbsa.global/wp-content/uploads/2021/02/EY-CBS-Cost-Effectiveness-Analysis. pdf

20. Ernst \& Young \& WSUP. (2017). The world can't wait for sewers: advancing container-based sanitation businesses as a viable answer to the global sanitation crisis. Retrieved June 19, 2021, from https://www. wsup.com/content/uploads/2017/08/Clean-Team-whitepaper.pdf

21. ESMAP. (2019). Mini grids for half a billion people. Retrieved June 19, 2021, from https://openknowledge. worldbank.org/bitstream/handle/10986/31926/Mini-Grids-for-Half-a-Billion-People-Market-Outlook-andHandbook-for-Decision-Makers-Executive-Summary.pdf?sequence=1\&isAllowed=y

22. Uptime. (2020). Results-based contracts for rural water services. Retrieved June 19, 2021, from https:// static1.squarespace.com/static/5d5fc19961d87c00011689d2/t/5f1759127e30ed322cd5dba0/ 1595365662058/Results-Based+Contracts+for+Rural+Water+Services.pdf

23. WHO \& UNICEF: JMP. (2017). Rural and urban sanitation service levels. Retrieved from https://washdata. org/data

24. WHO \& UNICEF: JMP. (2017). Rural and urban hygiene service levels. Retrieved from https://washdata. org/data,

25. AMSCLAE (Autoridad para el Manejo Sustentable de la Cuenca del Lago de Atitlán y su Entorno). (2019) Plan de Manejo Integrado de la Cuenca del Lago de Atitlán. Retrieved from https://www.amsclae.gob.gt/ 2020/01/15/plan-de-manejo-integrado-de-la-cuenca-del-lago-de-atitlan/

26. Ferráns, L., Caucci, S., Cifuentes, J., Avellán, T., Dornack, C., \& Hettiarachchi, H. (2018). Wastewater management in the basin of Lake Atitlan: a background study. United Nations University Institute for Integrated Management of Material Fluxes and of Resources (UNU-FLORES). Retrieved from https:// collections.unu.edu/eserv/UNU:6451/WorkingPaper_No6.pdf

27. AMSCLAE (Autoridad para el Manejo Sustentable de la Cuenca del Lago de Atitlán y su Entorno). (2019) Informe de Muestreo de las Plantas de Tratamiento de Aguas Residuales de la Cuenca del Lago de Atitlán. Retrieved from https://www.amsclae.gob.gt/wp-content/uploads/2019/12/ptar2019.pdf

28. Zabaleta I, Bulant N, Pfyffer B, Rohr M, Ivumbi E, Mwamlima P, Rajabu HM, Zurbrügg C (2018) Pyrolysis of biowaste in low and middle income settings: a step-by-step manual. Swiss Federal Institute of Aquatic Science and technology (Ewag), Dübendorf

29. Ngo, T. (2020). Pyrolysis in fecal sludge treatment. [Bachelor Thesis, Tampere University of Applied Sciences, Finland]. Retrieved from: https://www.theseus.fi/handle/10024/339898

30. Bleuler M, Gold M, Strande L, Schönborn A (2020) Pyrolysis of dry toilet substrate as a means of nutrient recycling in agricultural systems: potential risks and benefits. Waste Biomass Valor 12:4171-4183. https:// doi.org/10.1007/s12649-020-01220-0

31. de Coninck H, Revi A, Babiker M, Bertoldi P, Buckeridge M, Cartwright A, Dong W, Ford J, Fuss S, Hourcade JC, Ley D, Mechler R, Newman P, Revokatova A, Schultz S, Steg L, Sugiyama T (2018) Strengthening and implementing the global response. In: IPCC - The Intergovernmental Panel on Climate Change (ed) Global warming of $1.5^{\circ} \mathrm{C}$ : Summary for Policymakers, pp 313-443 Retrieved from https:// www.ipcc.ch/site/assets/uploads/sites/2/2019/05/SR15 Chapter4 Low Res.pdf

32. Gonçalves Lopes ÉM, Mendes Reis M, Almeida Frazão L, da Mata Terra LE, Lopes EF, dos Santos MM, Arnaldo Fernandes L (February, 2021) Biochar increases enzyme activity and total microbial quality of soil grown with sugarcane. Environ Technol Innov 21:101270. https://doi.org/10.1016/j.eti.2020.101270

33. Rehman A, Nawaz S, Alghamdi HA, Alrumman S, Yan W, Zohaib Nawaz M (2020) Effects of manurebased biochar on uptake of nutrients and water holding capacity of different types of soils. Case Stud Chem Environ Eng 2:100036. https://doi.org/10.1016/j.cscee.2020.100036

34. Kroeger JE, Pourhashem G, Medlock KB, Masiello CA (2020) Water cost savings from soil biochar amendment: a spatial analysis. GCB Bioenergy 13:133-142. https://doi.org/10.1111/gcbb.1276.5

35. Schmidt H-P, Pandit BH, Cornelissen G, Kammann C (2017)Biochar-based fertilization with liquid nutrient enrichment: 21 field trials covering 13 crop species in Nepal. Land Degrad Dev 28(8):2324-2342. https:// doi.org/10.1002/ldr.2761

36. Kizito S, Hongzhen L, Jiaxin L, Bah H, Dong R, Wu S (2019) Role of Nutrient-Enriched Biochar as a Soil Amendment during Maize Growth: Exploring Practical Alternatives to Recycle Agricultural Residuals and to Reduce Chemical Fertilizer Demand. Sustainability 11:113211. https://doi.org/10.3390/su11113211

37. Krause A, Häfner F, Augustin F, Udert KM (2021) Qualitative risk analysis for contents of dry toilets used to produce novel recycling fertilizers. Circ.Econ.Sust. https://doi.org/10.1007/s43615-021-00068-3

38. McConville, J. (2021). Guide to sanitation resource recovery products \& technologies, a supplement to the compendium of sanitation systems and Fe technologies. Retrieved from https:/www.slu.se/en/ew-news/ 
2021/1/guide-to-sanitation-resource-recovery-products\%2D\%2Dtechnologies-a-supplement-to-thecompendium-of-sanitation-systems-and-technologies/

39. Simha P, Friedrich C, Randall DG, Vinnerås B (2021) Alkaline dehydration of human urine collected in source-separated sanitation systems using magnesium oxide. Front Environ Sci 8:619901. https://doi.org/10. 3389/fenvs.2020.619901

40. Nature 596, 461 (2021), doi: https://doi.org/10.1038/d41586-021-02287-y

41. Reid MC, Guan K, Wagner F, Mauzerall DL (2014) Global methane emissions from pit latrines. Environ Sci Technol 48(15):8727-8734. https://doi.org/10.1021/es501549h

42. Irfan M, Chen Q, Yue Y, Pang R, Lin Q, Zhao X, Chen H (2016)Co-production of biochar, bio-oil and syngas from halophyte grass (Achnatherum splendens L.) under three different pyrolysis temperatures. Bioresour Technol 211:457-463. https://doi.org/10.1016/j.biortech.2016.03.077

43. The World Bank. (2019). GNI per capita (current LCU) - Guatemala. Retrieved June 20, 2021, from https:// data.worldbank.org/indicator/NY.GNP.PCAP.CN?locations=GT

44. FAO. (2006). Plant nutrition for food security: a guide for integrated nutrient management. http://www.fao. org/fileadmin/templates/soilbiodiversity/Downloadable_files/fpnb16.pdf

45. Convergence (C. (2021). Working Group on Blended Finance for Water Infrastructure Maintenance and Fecal Sludge Management - Outcome Document. Toronto, Canada. Retrieved from https://assets.ctfassets. net/4cgqlwde6qy0/5ZyT4cP5Y67MV0WAGdb3MX/d1a7bccff69f6281d22a840fc253bf34/Outcome_ Document_final.pdf

46. CBSA. (2018). Global leaders in household container based sanitation services: a comparative analysis. Retrieved June 20, 2021, from https://cbsa.global/wp-content/uploads/2020/10/cbsa-comparative-analysis. pdf

47. UCL, Trove Research, \& Liebreich Associates. (2021, June). Future demand, supply and prices for voluntary carbon credits - keeping the balance. https://trove-research.com/wp-content/uploads/2021/06/ Trove-Research-Carbon-Credit-Demand-Supply-and-Prices-1-June-2021.pdf

48. Gold Standard. (n.d.). Carbon pricing: what is a carbon credit worth? Retrieved June 28, 2021, from https:// www.goldstandard.org/blog-item/carbon-pricing-what-carbon-credit-worth

49. Carbon Gold. (n.d.). Fertiliser. Retrieved June 28, 2021, from https://www.carbongold.com/productcategory/fertiliser/

50. Sanders E, Stappers PJ (2008)Co-creation and the new landscapes of design. Codesign 4:5-18. https://doi. org/10.1080/15710880701875068

51. Müller F (2021) Design ethnography: epistemology and methodology. SpringerBriefs in Anthropology. https://doi.org/10.1007/978-3-030-60396-0 8

52. Drain A, Sanders E (2019) A collaboration system model for planning and evaluating participatory design projects. Int J Design 13(3):39-52 Retrieved from: http://www.ijdesign.org/index.php/IJDesign/article/ view/3486/870

53. Holmlid, S. (2009). Participative; co-operative; emancipatory: from participatory design to service design. [Conference presentation]. 1st Nordic Conference on Service Design and Service Innovation, Oslo, Norway. Retrieved from: https://servdes.org/conference-2009-oslo/

54. van der Velden M, Mörtberg C (2014) Participatory design and design for values. In: van den Hoven J, Veermas P, van de Poel I (eds) Handbook of Ethics, Values, and Technological Design. Springer, Dordrecht. https://doi.org/10.1007/978-94-007-6994-6_33-1

55. Kensing F, Greenbaum J (2013) Heritage: having a say. Routledge International Handbook of Participatory Design. Routledge, New York, pp 21-36. https://doi.org/10.1007/978-94-007-6994-6_33-1

56. Elías S. (2020). Indigenous World 2020: Guatemala. Article of the 34th edition of The Indigenous World. IWGIA - International Work Group for Indigenous Affairs. Retrieved from https:/www.iwgia.org/en/ guatemala/3622-iw-2020-guatemala.html

57. Young S, Brownotter C (2018) Toward a more just library: participatory design with native american students. Weave - J Library User Exper 1(9):2. https://doi.org/10.3998/weave.12535642.0001.901

58. Hoffecker E (2019) Understanding innovation ecosystems: a framework for joint analysis and action. MIT D-Lab, Cambridge Retrieved from https://d-lab.mit.edu/sites/default/files/inline-files/Understanding Innovation_Ecosystems_FINAL_JULY2019.pdf

59. Promote Handwashing (2017). The global handwashing partnership (GHP). Retrieved from https:// globalhandwashing.org/about-handwashing/promote-handwashing/

60. Hussain S (2010) Empowering marginalised children in developing countries through participatory design processes. CoDesign 6(2):99-117. https://doi.org/10.1080/15710882.2010.499467

61. Lüthi C, Morel A, Tilley E, Ulrich L (2011)Community-led urban environmental sanitation planning (CLUES) Swiss Federal Institute of Aquatic Science and Technology (Eawag). Dübendorf, Switzerland Retrieved from https://www.susana.org/en/knowledge-hub/resources-and-publications/library/details/1300 
62. Mosan (2020) Our background: past pilot \& research projects. Retrieved March 26, 2021, from https:// mosan.ch/history/

63. Hofstede G, Minkov M (1991) Cultures and organizations: software of the mind. McGraw-Hill, London ISBN 10: 0071770151

64. Taha KA (2011) Creative capacity building in post-conflict Uganda. Doctoral dissertation, Massachusetts Institute of Technology, Massachusetts Retrieved from https://dspace.mit.edu/handle/1721.1/63238

65. MIT D-Lab (2018). D-Lab Fall Student Showcase 2018: 24 projects in 15 countries engaging 96 students. Retrieved from https://d-lab.mit.edu/news-blog/news/d-lab-fall-student-showcase-2018-24-projects-15countries-engaging-96-students

66. Vogel, S. (2021)Co-creating a more equitable world: the transformative benefits of participatory design. Retrieved from https://d-lab.mit.edu/news-blog/blog/co-creating-more-equitable-world-transformativebenefits-participatory-design

67. Schroder HS, Moran TP, Donnellan MB, Mose JS (2014) Mindset induction effects on cognitive control: a neurobehavioral investigation. Biol Psychol 103:27-37, ISSN 0301-0511. https://doi.org/10.1016/j. biopsycho.2014.08.004

68. Cottam H, Leadbeater C (2004) Health: co-creating services. In: Red paper 01. Council, The Design Retrieved from http://www.designcouncil.info/mt/RED/health/REDPaper01.pdf

69. Link4 (2020). Retrieved 17 March 2021 from https://www.link4.gt

70. Brandt E, Binder T, Sanders E (2012) Tools and techniques: ways to engage telling, making and enacting. In: Routledge International Handbook of Participatory Design. Routledge International Handbooks, U.K., pp $145-181$

71. Morris BS, Chrysochou P, Christensen JD, Orquin JL, Barraza J, Zak PJ, Mitkidis P (2019) Stories vs. facts: triggering emotion and action-taking on climate change. Clim Chang 154:19-36. https://doi.org/10.1007/ s10584-019-02425-6

72. McKown, L. (2016), Sustainable homes, sustainable partnerships: building a design for development ecosystem in Guatemala, Retrieved 17 March 2021 from http://idin.org/blog-news-events/blog/threetools-inclusive-innovation

73. Meyer, E. (2014). The culture map: breaking through the invisible boundaries of global business. PublicAffairs, U.S. ISBN 10: 1610392507

74. Hoffecker E (2018) Local innovation: what it is and why it matters for developing economies. In: D-Lab Working Papers: NDIR Working Paper 01. MIT D-Lab, Cambridge 